\title{
Franz KafKa: A UltrapasSAGEM dA BUROCRATIZAÇÃo DA INSTÂNCIA PATERNA E DA VOZ ÁFONA DO SUPEREU
}

\begin{abstract}
Resumo
Este artigo mostra que a crítica literária (Benjamin, Blanchot, Gagnebin e Carone) leu a burocratização da instância paterna presente na poética de Kafka como uma neutralização da voz narrativa e toma, com a psicanálise, essa neutralização como uma manifestação da voz áfona do supereu (Lacan e Zizek). Discute as diferenças entre uma versão do pai cuja Lei se une ao desejo e, uma outra, insensata e caprichosa, que serve ao gozo. Finaliza indagando a função da literatura para o escritor tcheco
\end{abstract}

Palavras-chave: neutralização do narrador; voz áfona do supereu; ardis ficcionais.

\section{Franz KafKa: THE PASSING OF THE FATHER'S BUREAUCRATIZATION AND OF THE SUPER-EGO SILENT VOICE}

\begin{abstract}
This article shows that literary criticism (Benjamin, Blanchot, Gagnebin and Carone) read the bureaucratization of the paternal instance of Kafka's poetics as a neutralization of the narrative voice and takes this, with psychoanalysis, as a manifestation of the silent voice of the superego (Lacan and Zizek). It discusses the differences between a version of the father whose Law joins the desire, and another, capricious and unreasonable, which serves jouissance. It ends questioning the function of literature to the Czech writer
\end{abstract}

Keywords: The narrator's neutralization; superego silent voice; fictional tricks.

\footnotetext{
^ Psicóloga. Psicanalista. Doutora em Literatura Comparada pela Universidade Federal de Minas Gerais, Pós-Doutorado em Teoria Psicanalítica pela Universidade Federal do Rio de Janeiro), Profa . na Pós-Graduação em Psicologia (UFMG). Membro da Escola Brasileira de Psicanálise e da Associação Mundial de Psicanálise. Endereço: Rua Levindo Lopes, 333 sala 305. Savassi.. Belo Horizonte. MG. CEP: 30140911

E-mail:marcia.rosa@globo.com
} 
"Prova de que recursos insuficientes, e até pueris, podem servir à salvação.” (KAFKA, 1987, p. 38).

Ao tratar o mito individual do neurótico no início dos anos 1950, Jacques Lacan observou que "em uma estrutura social como a nossa o pai é sempre, de algum modo, um pai discordante relativamente à sua função, um pai carente, um pai humilhado [...]" (LACAN, 2008[1952], p. 40). Uma dezena de anos depois, para discutir o que denominou o mito de Édipo na contemporaneidade ele fez um longo comentário da trilogia dos Coûfontaine (1908-1916) de Paul Claudel (1868-1955), mostrando que não se trata aí de outra coisa senão do pai que, no terceiro livro da série O pai humilhado (1967[1915-1916]), sofre uma derrisão radical, uma "derrisão que confina com o abjeto" (LACAN, 1992[1961], p. 279).

A versão claudeliana da instância paterna, derrisória, uma vez que o pai morre literalmente de medo, e abjeta, uma vez que na sua avareza ele não se poupa de expropriar o próprio filho, encontra no horizonte subjetivo do início do século XX um outro tratamento derrisório da instância paterna, aquele trazido pela poética do escritor tcheco, Franz Kafka (1883-1924). Sem assumir a forma das narrações míticas universais, a literatura kafkiana trata de modo constante e progressivo o tema da Lei e, em especial, da Lei paterna. ${ }^{1}$ Isso se evidencia inclusive pelo fato de o escritor ter chegado a considerar em 1916 a possibilidade de publicar um volume intitulado "Punições", no qual incluiria três dos seus trabalhos anteriores: O veredicto (1912), A metamorfose (1915) e Na Colônia Penal (1914). Em O Veredicto (KAFKA, 1998[1912]), surpreendemo-nos com o despertar aparentemente imotivado e caprichoso da ira paterna, ira que dará lugar ao enunciado de uma sentença de morte ("eu o condeno à morte por afogamento") que o filho se apressará em cumprir. Em A Metamorfose (KAFKA, 1965[1915]), um dia o filho acorda transformado em inseto e enfrenta o poder destrutivo do pai. Em Na Colônia Penal (KAFKA, 1998[1914]), temos um observador que assiste a uma cerimônia de tortura e execução, cerimônia levada a efeito por uma máquina, operada por um oficial, que escreve nas costas de cada condenado a sentença que the cabe: o sujeito recebe assim, na carne, o peso da Lei.

Comentarista e tradutor para o português da obra de Kafka, Modesto Carone observa a presença de uma mudança na instância paterna no decorrer da trilogia: isolado em $O$ Veredicto (KAFKA, 1998[1912]), apoiado na família em A Metamorfose (KAFKA, 1965[1915]), o pai é distribuído por dois sistemas concorrentes em Na Colônia Penal (KAFKA, 1998[1914]). A Metamorfose (KAFKA, 1965[1915]), por sua vez, "marca a transição do que ainda é pessoal para o que vai deixar de sê-lo, fenômeno que um crítico descreveu como uma burocratização da figura paterna" (CARONE, 1999[1988], p. 75). Este trabalho de despersonalização da figura e da Lei paternas encontra seu ápice em $O$ Processo (KAFKA, 2001b). “uma vez que neste a função de culpar, condenar e proceder à execução do herói se transfere das mãos do patriarca para uma instância anônima — o Tribunal" (CARONE, 1999[1988], p. 75)). 
Em vista disso, interessa-nos mostrar o modo como a crítica literária (em especial aquela feita por Benjamin, Blanchot, Gagnebin e Carone) leu a despersonalização ou burocratização da instância paterna como uma neutralização da voz narrativa, para, a seguir, tomar essa neutralização como uma manifestação da voz áfona do supereu, leitura que traz a marca da psicanálise. Depois de discutir as diferenças entre uma versão do pai cuja Lei se une ao desejo e, uma outra, insensata e caprichosa, que serve ao gozo, finalizaremos indagando a função da literatura para o escritor tcheco.

\section{Parte 1 - Kafka com Benjamin e Blanchot: A NEUTRALIZAÇÃO DA VOZ NARRATIVA}

Aos olhos do ensaísta e crítico literário Walter Benjamin (1892-1940), se fosse possível conceber um sujeito que na época da invenção do cinema não reconheceria seu próprio andar, que nos tempos do gramofone não reconheceria sua própria voz, ele não seria outro senão Franz Kafka. Além da transmissão de uma inquietante estranheza (Unheimlich, em termos freudianos), a obra do escritor tcheco tenta fixar alguma coisa que não compreende e que se apresenta em suas parábolas como um elemento nebuloso. Desse elemento partiria a obra literária de Kafka (BENJAMIN, 1985a, p.154).

Em meados dos anos 30, o crítico literário observou que a arte de narrar estava em extinção uma vez que as ações da experiência estavam em baixa e que a fonte a que recorrem todos os narradores é exatamente a experiência que passa de pessoa a pessoa (BENJAMIN, 1985b, p. 198). Apresentadas como "radicalmente desmoralizadoras", as experiências em curso naquela época levam o ensaísta a diagnosticar a existência de uma pobreza em experiências comunicáveis. Dois anos antes deste ensaio sobre a narração, Benjamin homenageara o escritor tcheco. No texto de sua homenagem, apaixonante por sinal, ele nos desperta, logo de saída, o desejo de ler Kafka e nos transmite um entusiasmo que, certamente, ele próprio experimentava em relação à obra desse escritor.

Benjamin (1985a, p. 154) visa "lançar alguma luz sobre as forças arcaicas que atravessam a obra de Kafka - forças, entretanto, que com igual justificação poderíamos identificar no mundo contemporâneo". Se é impossível dizer sob qual nome elas apareceram a Kafka, certo é que ele não se encontrou nelas, afirma o nosso ensaísta. Assim, em vez de conclusões especulativas, ele homenageia Kafka ao retornar à sua obra para uma investigação temática dos seus contos e romances.

Consagrado tradutor de Kafka para o português, Modesto Carone (2000, online) inclui o ensaio de Benjamin sobre Franz Kafka na "ala esquerda da crítica kafkiana [a qual] repudiou a tendência à alegorização como uma simplificação indevida, que acabava provando as próprias teses e deixava a obra de lado". Ao destacar a questão da narração, Carone, ele próprio, observa a presença no texto de Kafka de uma formalização literária do estado de coisas contemporâneo, já que o narrador não apenas deixou de ser onisciente, assim como se tornou insciente: 
[...] diante do impasse moderno da perda da noção de totalidade, aquele que narra, em Kafka, não sabe nada ou quase nada sobre o que de fato acontece - do mesmo modo, portanto, que o personagem. Trata-se, quando muito, de visões parceladas, e é essa circunstância que obscurece o horizonte da narrativa e obriga quem lê a mapear por dentro a falsa consciência - se se quiser, a alienação —, pois o narrador não tem chance de ser um agente esclarecedor ou 'iluminista' (CARONE, 2000, online).

Que o autor de $O$ Processo (KAFKA, 2001b) não se reconhecesse nos gadgets ${ }^{2}$ produzidos pela era da reprodutibilidade técnica (BENJAMIN, 1985c) - nascidos no tempo da mais profunda alienação dos homens —, não implica que a tradição lhe oferecesse melhores possibilidades de ancoragem. O culto a um Patriarca mantido à distância e iluminado pela fé como um objeto aurático cede lugar a uma figura mais claudeliana de pai. ${ }^{4}$ Introduzir um adiamento, um impedimento no gesto do Patriarca - a serviço do Outro da religião com a solicitude de um garçom - , não deixa de dessacralizá-lo, de rebaixá-lo e, também, à tradição da qual ele tira sua aura. Deixar para depois o sacrifício é a esperança dos acusados, e o escritor tcheco sugere que esse adiamento beneficiaria até mesmo o Patriarca, se ele se dispusesse a "renunciar ao papel que lhe cabe na tradição" (BENJAMIN, 1985a, p. 154). Isso fica evidente no modo inusitado como Kafka (apud BENJAMIN, 1985a, p.154) a apresenta:

Posso imaginar um outro Abraão, que não chegaria evidentemente à condição de Patriarca, nem sequer à de negociante de roupas usadas, que se disporia a cumprir a exigência do sacrifício, obsequioso como um garçom, mas que não consumaria esse sacrifício, porque não pode sair de casa, onde é indispensável, porque seus negócios lhe impõem obrigações, porque há sempre alguma coisa a arrumar, porque a casa não esta pronta, e sem que ela esteja pronta não pode sair, como a própria Bíblia admite, quando diz: ele pôs em ordem sua casa.

Além do adiamento, na literatura kafkiana:

[...] o pai é a figura que pune. A culpa o atrai, como atrai os funcionários da Justiça. Há muitos indícios de que o mundo dos funcionários e o mundo dos pais são idênticos para Kafka. Essa semelhança não os honra. Ela é feita de estupidez, degradação e imundície. O uniforme do pai é cheio de nódoas, sua roupa de baixo é suja. A imundície é o elemento vital do funcionário (BENJAMIN, 1985a, p.139).

A atração pela culpa une o pai aos funcionários da Justiça, degradando-os e lançando na abjeção o mundo do funcionalismo e em seu funcionamento burocrático. Se nos servirmos da teoria da burocracia, tal como a concebeu Max Weber 
(2010) em seu A ética protestante e o espírito do capitalismo, encontramos entre seus elementos definidores uma impessoalidade que faz com que os funcionários se limitem a cumprir tarefas em um funcionamento considerado completamente previsível, dado que fundado em normas e regulamentos rígidos que acabam sendo um fim em si mesmos. Além dessa última, a burocracia gera disfunções tais como um formalismo excessivo, uma conformidade à rotina, uma incapacidade de lidar com a informalidade e a variabilidade humana e, essencial para o que nos interessa no momento, uma despersonalização. Posto isso, ao aproximar o pai dos funcionários da Justiça, Kafka deixa subentendida uma leitura da função paterna não apenas pela via de uma satisfação pulsional perversa, uma vez que atraídos pela culpa, mas também pela via da burocracia, ou seja, da impessoalidade, da despersonalização e, last but not least, do anonimato.

A dita burocratização da figura paterna apresenta-se na voz narrativa através de uma neutralização: "ele" fala = ninguém fala. Para Maurice Blanchot (1991, p. 234), Kafka nos mostra que contar põe em jogo o neutro, o "ele" que "não é uma terceira pessoa, nem tampouco a simples coberta da impessoalidade". Essa narrativa neutra, que destitui o sujeito, "nos faz pressentir que o que se conta não é contado por ninguém: fala em neutro" (BLANCHOT, 1991, p. 234), e que nesse espaço neutro da narração os personagens sofrem um processo de desidentificação consigo mesmos, desprendendo-se de sua capacidade de dizer "eu". Esquecidos de si, esses portadores da palavra, designados personagens, são introduzidos "no presente sem memória que é a palavra narrativa" (BLANCHOT, 1991, p. 234). Assim, conclui o escritor francês, "contar é pôr-se à prova desse esquecimento primitivo que precede, funda e estraga qualquer memória. [...] contar é o tormento da linguagem, a busca incessante de sua infinidade" (BLANCHOT, 1991, p. 234).

O "ele" seria, portanto, um vazio na obra, uma palavra-ausência, ou uma palavra-buraco. Essa palavra "não teria podido dizer-se, mas ter-se-ia podido fazê-la ressoar: imensa, sem fim, como um gongo vazio" (BLANCHOT, 1991, p. 236-237). ${ }^{3}$ Portanto:

[...] ausente ou presente, afirme-se ou se subtraia, altere ou não os convencionalismos da escritura - a linearidade, a continuidade, a legibilidade —, o "ele" narrativo marca assim a irrupção do outro — entendido em neutro — em sua estranheza irredutível, em sua perversidade retorcida. $\mathrm{O}$ outro fala, mas quando ele fala ninguém fala [...] A voz narrativa (não digo narradora) obtém daí sua afonia (BLANCHOT, 1991, p. 236, grifo nosso).

Cabe enfatizar esse oximoro, "uma voz áfona", que surge precisamente como efeito do processo de neutralização: se o sujeito foi neutralizado, se quando ele fala, ninguém fala, temos não apenas uma impessoalidade e um anonimato, mas também uma instância narrativa de algum modo emudecida. Para Blanchot, a impessoalidade é a encarnação mesma da "distância estética". O escritor suprime as relações entre ele e a novela de modo a atingir o ideal trazido pelo teatro 
clássico, no qual o narrador só está presente para levantar a tela. Nessa perspectiva, "o autor não conta, mostra, e o leitor não lê, olha, assistindo, tomando parte sem participar" (BLANCHOT, 1991, p. 229). Para o ensaísta francês, a operação narrativa kafkiana traz a distância para o centro da obra: o personagem principal não apenas vive à distância, como está sempre à distância dos acontecimentos, dos seus conhecidos, distanciado de si mesmo, e, igualmente, apartado do centro da obra (que está, portanto, descentrada). Desse modo, o leitor é desalojado da irresponsabilidade contemplativa, da posição de gozo contemplativo, na qual fora instalado pela perspectiva clássica. Ao re-introduzir essa estranha distância que se transforma em uma espécie de substância da obra —, Kafka faz com que o leitor não possa mais gozar da obra com desinteresse; ele é convocado a se aproximar de algo do qual "não lhe é possível tomar distância com tanta facilidade" (BLANCHOT, 1991, p. 232-233).

Depois de assinalar o fato de que o esquecimento da tradição, sagrada ou profana, "engendra uma narratividade neutra, sem laços nem apoios", Jeanne Marie Gagnebin (1994, p. 79-80), por sua vez, evoca "a crueldade dessas narrativas nas quais a autoridade pode se transformar num arbitrário tanto mais poderoso quanto ele não remete a nenhum fundamento, fora a um morto, como Na Colônia Penal". No entanto, a ensaísta assinala a dimensão paradoxal dessa neutralidade já que surge daí a sua estranha serenidade, isto é, "a palavra, aliviada da preocupação com a origem, assume seu percurso arbitrário e reinventa sua própria lei [...]" (GAGNEBIN, 1994, p. 79-80).

\section{Parte 2 - Kafka CoM Zizek e Lacan: A VOZ ÁFONA do SUPEREU E AS VERSÕES DA LEI}

Para o filósofo esloveno, Slavoj Zizek, a neutralização kafkiana da voz narrativa é uma presentificação da voz áfona do supereu. Ao ir nessa direção, ele diz ser esse "o modo de funcionamento libidinal da burocracia totalitária" (ZIZEK, 1983, p. 24), isto é, ao faltar um ponto de amarração no seu discurso, a lei passa a funcionar como supereu. No seu entender, a burocracia torna-se totalitária no momento em que desaparece o ponto de exceção não burocrático que a totaliza de fora. Se, como diz o ditado, toda regra tem exceção, ao faltar a exceção, o saber burocrático (a regra) enlouquece: sua neutralidade surge como malévola, sua indiferença provoca no sujeito o efeito totalitário do imperativo do supereu: ${ }^{4}$

Obedeça! Sacrifique! Faça teu dever! [...] [Obedeça — a quê? Sacrifique — por quê? Faça seu dever — qual?] Não havendo nenhum ponto de amarração (já que a voz narrativa encontra-se neutralizada, bem como dessubjetivada), a resposta torna-se tautológica e faz com que o sujeito acabe girando em círculo: obedeça porque é necessário obedecer! É necessário porque... é necessário! (ZIZEK, 1983, p. 25)" 
Se se quer a qualquer custo, afirma Zizek, encontrar a base social refletida na obra de Kafka, não seria equivocado dizer que no universo desse jurista, que se transformou em escritor, "a lei funciona como um imperativo não-dialetizado" (ZIZEK, 1983, p. 24). Isso, acrescenta ele, é o que ocorre na "passagem da sociedade burguesa liberal para a sociedade totalitária pós-liberal, dominada pela burocracia" (ZIZEK, 1983, p. 24). Nesse ponto de virada, a liberdade de gozar transforma-se em obrigação de gozar, forma bastante efetiva de bloquear qualquer acesso do sujeito ao gozo.

Ao funcionar como um imperativo não dialetizado, a Lei apresenta-se como uma encarnação do supereu. Se a verdadeira função do Pai é, "essencialmente, unir (e não opor) um desejo à Lei” (LACAN, 1998 [1960], p. 839), o supereu é uma espécie de patogenia dessa relação na medida em que é resultante da incorporação de uma autoridade paterna inatacável cuja severidade não poupará o sujeito, apresentando-se como uma Lei insensata e cruel que "emite uma ordem e não pergunta se é possível obedecê-la" (FREUD, 1974[1930], p. 168). Disso resulta não apenas um sentimento inconsciente de culpa e uma necessidade de punição, mas também uma espécie de mal-estar na civilização, uma vez que as renúncias à satisfação pulsional ao invés de pacificarem as exigências deste Outro superegóico, não fazem senão aumentar a sua severidade (FREUD, 1974[1930]), ou, nos termos de Lacan, a sua "gulodice" (LACAN, 2003[1974], p. 528).

A tradição nos brinda com "figura[s] obscena[s] e feroz[es]" do supereu (LACAN, 1988[1960], p. 16), figuras que encarnam de modo imaginário a autoridade na medida em que se identificam e se confundem com ela. No campo do simbólico, o supereu apresenta-se como uma Lei insensata e caprichosa uma vez que sustentada em um buraco, em uma ausência de justificação: "é a lei como significante unário, S1, cuja significação desconhecemos, pois para conhecê-la seria necessário um segundo significante a partir do qual o primeiro ganharia sentido retroativamente" (MILLER, 2009[1981], p. 138).

No registro do real, o supereu é o objeto pequeno a como voz. Ao operar como tal, ao invés de unir o desejo à Lei, ele se opõe ao desejo e funciona como um imperativo de gozo, como uma voz que ordena: Goza! [Jouis!]. Portanto, “[...] em seu imperativo íntimo, [o supereu] é de fato 'a voz da consciência', isto é, antes de mais nada uma voz" (LACAN, 1998[1960], p. 691), uma voz diante da qual "o sujeito só poderia responder [...] com um Ouço! [J'ouis!]" (LACAN, 1998[1960], p. 836). Categórica e imperativa, essa voz conduz a um paradoxo na medida em que quanto mais virtuoso o sujeito, maior o sentimento de estar em falta, maior o sentimento inconsciente de culpa e a necessidade de punição. Isso explica o comentário de Jacques Alain-Miller (2009[1981]) segundo o qual, o supereu encontra seu lugar em Lacan com o nome de gozo e deve ser incluído em uma série comum com a pulsão de morte e o masoquismo primordial.

Ao se ligar a pulsão de morte o supereu evidencia uma falha na Lei e essa passa a funcionar na sua face desreguladora. Constituído a partir de restos das palavras ouvidas, restos da voz do Outro, o supereu opera: 
[...] como voz muda que age como pura enunciação, convocando o sujeito à expiação da culpa. Essa voz que aparece desde os primórdios do texto freudiano como censura opõe-se ao desejo inconsciente e mostra a precariedade da lei edipiana. Ela se manifesta como patogenia da lei, na medida em que pode deixar de ser reguladora e se voltar contra o sujeito, impondo-lhe exigências insaciáveis (GOMES, 2003, p. 279-280.).

Se o texto kafkiano se constrói e gira em torno de um elemento obscuro. Obscuridade que faz com que o escritor não se reconheça em sua própria voz, nem na tradição e tão pouco nas forças arcaicas que toma como temática, acreditamos que esse elemento obscuro iluminar-se-ia se lido como uma manifestação do supereu. Ao neutralizar a função paterna em sua eficácia -eficácia gerada precisamente a partir do Nome-do-Pai enquanto instância não anônima e enquanto instância nominante —, ao despersonalizar ou burocratizar o Pai em sua função de unir o desejo à Lei, o texto kafkiano encontra exatamente a outra face da Lei, a sua face cruel, insensata e caprichosa. Isto é gritante nos livros que comporiam a trilogia sobre as punições, na qual o pai é um poder destrutivo e caprichoso no exercício de sua ira, de sua sentença de morte e do agenciamento da tortura. Se, no texto freudiano, o supereu é herdeiro da noção de censura ou de censor, ele apresenta-se dividido em uma parte acessível e reconhecida pelo sujeito e em uma outra, inadmissível e inassimilada, que indica exatamente um ponto no qual a lei não é compreendida pelo sujeito. Diante desse poder despótico e cruel, o texto kafkiano se serve do recurso à degradação, à abjeção, do adiamento, da retirada da aura que a tradição confere ao Outro; todos esses recuros podem ser lidos como formas de barrar esse Outro gozador e de tentar unir o desejo à Lei. Obviamente, esse Outro está construído na exata medida da posição fantasmática do sujeito. Para ele, era como se "as relações com os objetos, acontecimentos e pessoas só fossem visíveis nos hieróglifos da dor e do medo" (CARONE, 1998[1988], p. 77).

No entanto, como bem observa Benjamin, se é da Justiça que parte em Kafka a crítica ao mito, e, acrescentemos, em especial, aos mitos paternos, não é o Direito nem a Lei jurídica que serão mobilizados contra ele, mas as leis da linguagem, ou seja, a literatura.

\section{PARTe 3 - Os ARdis do ESCRITOR OU A FUnÇÃo da literatura}

Benjamin afirma que a obra de Kafka representa uma "doença da tradição" (KAFKA, 1993[1938], p.105 ) e que nesse sentido ela torna evidente que a consistência da verdade se perdeu. Assim, no lugar da Lei, da doutrina, da tradição — seja ela religiosa, psicanalítica, filosófica e, até mesmo ( por que não dizer?), literária —-, teríamos um esquecimento. Ao evidenciar essa doença sem tentar curá-la, levando-a ao seu limite, Kafka desiste:

[...] do modelo habitual que dá por tarefa à literatura a expressão de uma verdade exterior e fundadora [...] Se o 
esquecimento da tradição, em particular da Lei, é bem a culpa desconhecida que deve ser expiada indefinidamente, esta espécie de vazio turvo e inquieto no qual se movem as personagens de Kafka, é o indício de uma outra lei: a da literatura (GAGNEBIN, 1994, p. 79-80).

Se “Kafka não cedeu à sedução do mito" (BENJAMIN, 1985a, p. 143), torna-se possível contrapor "a memória perturbadora do romancista", consagrada a um herói, a uma peregrinação, a um combate e "a breve memória do narrador" (BENJAMIN, 1985a, p. 211) que leva a muitos fatos difusos. Se o romancista centra-se no um, o narrador descentra-se no múltiplo. Esboçam-se assim alguns marcos tímidos para definir uma atividade narrativa que saberia rememorar e recolher o passado esparso sem, no entanto, assumir a forma obsoleta das narrações míticas universais, denominadas por Lyotard grandes narrativas legitimadoras 5 (GAGNEBIN, 1994, p. 71).

Encontramos na ficção kafkiana tanto o romancista centrado no um, textos como O processo, A metamorfose, Na Colônia Penal, etc. incluir-se-iam nessa categoria, quanto o narrador descentrado. "Pequenas narrativas" chega a ser o subtítulo do livro Um médico rural (KAFKA, 1999). Incluem-se entre essas últimas as "parábolas e fragmentos", publicadas postumamente a contragosto do desejo do escritor. Kafka surge aí, no dito de um crítico, "inteiro em fragmentos" (CAMPOS, 1987, p. 17).

Assim, ao lado da poética kafkiana, cujo universo ficcional é tomado pela desesperança e pela burocracia do supereu, na qual encontramos traços (' $Z u g$ ' e não 'Spur' ${ }^{6}$ ) fantasmáticos que localizam o sujeito em uma posição essencialmente masoquista, ${ }^{7}$ posição de filho se fazendo punir de modo implacável pelo pai, emerge uma outra, a das pequenas parábolas, das pequenas inversões e dos pequenos truques. A função da literatura parece ser evocada aí não apenas como expressão da verdade, como responsabilidade ética e política, mas também como entretenimento, isto é, enquanto exercício de linguagem que, sem desconhecer a responsabilidade, contribui para que "o dorso seja aliviado de seu fardo" (BENJAMIN, 1985a, p. 164).

Não parece equivocado supor que ao introduzir pequenos truques nos mitos, nas lendas, nas narrativas clássicas (tal como o de um Abraão que não consegue realizar o sacrifício porque padece de uma posição sintomática de protelação), o prosador tcheco teria se salvo. Não é senão ardilosamente que ele opera uma espécie de resgate da função dos contos de fadas na medida em que eles "nos revela[riam] as primeiras medidas tomadas pela humanidade para libertarse do pesadelo mítico" (BENJAMIN, 1985a, p. 215). No entanto, à diferença da criança de Hans Anderson, que desvela a nudez do rei, a criança kafkiana, criança-correio-do-rei, traz a mensagem sem sentido de um rei que não existe, ou melhor, traz a mensagem de que o rei não existe! (Ele sequer estaria morto, como no texto "Uma mensagem Imperial".) (KAFKA, 1987, p. 24). 


\section{Conclusão}

Por que, afinal, o mito constituir-se-ia em pesadelo para Kafka? Para abordá-lo, torna-se interessante ir além dos mitos paternos, tratados no decorrer deste texto pelo duplo viés da Lei como regulação e desregulação. Se o mito participa destas "ficções que racionalizam o impossível" (LACAN, 2003[1974], p. 531) ou que tornam transmissível algo da verdade que não seria transmissível de outro modo, ao recusá-lo Kafka estaria recusando à sua literatura o estatuto de um empreendimento fundado sobre a verdade? Sem dúvida, o texto kafkiano não se presta bem à posição de uma escritura enigmática a ser decifrada em seu recalcamento, caso no qual teria o estatuto de uma escritura do sintoma enquanto formação do inconsciente. Nem tão pouco, o texto kafkiano tem a função de uma escritura sinthomática cuja função seria a de amarração dos registros real, simbólico e imaginário e de suprir a carência paterna. Pelo que vimos, poderíamos afirmar termos aí uma poética do fantasma, uma poética marcada pela presença de personagens colocados em relação ao objeto voz, voz muitas vezes áfona, voz obscena e cruel que conduz a uma satisfação masoquista. No entanto, temos também um outro tipo de escritos nos quais Kafka nos brinda com um exercício lúdico, irreverente e ardiloso da literatura.

Depois de ter produzido uma travessia dos ideais da civilização veiculados pela tradição (paterna) e de ter feito emergir os traços (Zug) fantasmáticos, uma nova inversão ocorre, um giro a mais, e o texto parece surgir na sua dimensão eminentemente ficcional, lúdica. Se forem esses os seus giros, a literatura kafkiana não deixa de evocar o percurso de uma psicanálise. Nesse sentido, ao ultrapassar a burocratização da figura paterna e a voz áfona do supereu, o tratamento kafkiano da instância paterna faria surgir o pai no seu estatuto ficcional de semblante. ${ }^{8} \mathrm{O}$ ardil do escritor evidenciar-se-ia, então, nessas "Odisséia [s] em miniatura" 9 tal como "A verdade sobre Sancho":

Sancho Panza, que disto aliás nunca se gabou, através de uma porção de romances de cavalaria e aventuras lidos em horas da tarde e da noite, com o correr dos anos chegou a desviar-se do seu Diabo - a quem mais tarde deu o nome de Dom Quixote - a tal ponto que este, completamente solto, meteu-se nas mais alucinadas proezas... as quais todavia, por falta de objetivo predeterminado (que poderia ter sido Sancho Pança em pessoa) não fizeram mal a ninguém. Sancho Panza, homem livre, talvez por um sabido senso de responsabilidade, impassível acompanhava Dom Quixote em suas saídas, tendo com elas farto e proveitoso divertimento até o fim da vida. (KAFKA, 1987, p. 44).

Teria o dorso finalmente sido aliviado de seu fardo? 


\section{Notas}

${ }^{1}$ Tratei dessas questões no artigo "A arte aplicada à Psicanálise” (ROSA, 2001).

${ }^{2}$ Gadget (em inglês: geringonça, dispositivo) é um equipamento que tem um propósito e uma função específica, prática e útil no cotidiano. São comumente chamados de gadgets dispositivos eletrônicos portáteis como PDAs, celulares, smartphones, leitores de mp3, entre outros. Em outras palavras, é uma "geringonça" eletrônica. Além de seu mencionado uso como gíria tecnológica, cabe pontuar que o termo "gadget" ganha contornos específicos no campo da Psicanálise quando, na segunda metade do século XX, o psicanalista francês Jacques Lacan passa a dele fazer uso para referir-se aos objetos de consumo produzidos e ofertados como se fossem "desejos" pela lógica capitalista - na qual estão agregados o saber científico e as tecnologias em geral. Entre esses gadgets, diz Lacan, encontram-se os "sujeitos-mercadorias", aqueles que incorporam de forma um tanto psicótica uma atitude de objetos de consumo breve e que, por isso, investem suas energias em provar-se "consumíveis" ou "desejáveis" aos olhos de eventuais parceiros ou do mercado, o grande senhor contemporâneo. Pela perspectiva lacaniana estes sujeitos-mercadoria não são de fato sujeitos, já que consomem "objetos" e ofertam-se ao consumo por "objetos", não ao estabelecimento de laços sociais. (http://pt.wikipedia.org/wiki/Gadget. Acesso: maio 2011).

${ }^{3}$ Blanchot serve-se aí de um comentário feito por Marguerite Duras.

${ }^{4}$ Ao tomar um exemplo, Zizek mostra que em um sistema monárquico esse ponto de exceção seria encarnado pelo monarca.

${ }^{5}$ Cabe retomar Lyotard (1993, p. XV-XVI) quando comenta: “ [...] o relato das Luzes, onde o herói do saber trabalha por um bom fim ético-político, a paz universal. Vê-se neste caso, legitimando o saber por um metarrelato, que implica uma filosofia da história. [...] considera-se 'pós-moderna' a incredulidade em relação aos metarrelatos. [...] A função narrativa perde seus atores (functeurs), os grandes heróis, os grandes périplos e o grande objetivo. Ela se dispersa em nuvens de elementos de linguagem narrativos, mas também denotativos, prescritivos, etc., cada um veiculando consigo validades pragmáticas sui generis. [...] Assim nasce uma sociedade [na qual] existem muitos jogos de linguagem diferentes; trata-se da heterogeneidade dos elementos. Somente darão origem à instituição através de placas; é o determinismo local".

${ }^{6}$ Freud utiliza 'Spur' para os traços de memória; o 'Zug' é usado não apenas referindo-se ao traço unário, 'einzinger Zug', (marca, emblema, distintivo do sujeito), mas também quando fala do traço primário de perversão (primaren Zug).

${ }^{7}$ A Carta ao Pai (KAFKA, 2001a), mostra que está em jogo aí não apenas o sujeito ficcional, mas, também, o sujeito-autor. "Era como se as suas relações com os objetos, acontecimentos e pessoas só fossem visíveis nos hieróglifos da dor e do medo", diz Carone (1999[1988], p.77).

${ }^{8}$ Com a noção de semblante, originada da discussão sobre os simulacros, em Platão, Lacan dá ao simbólico e ao imaginário, à verdade e à aparência, o mesmo valor. O oposto do verdadeiro não é o mentiroso, mas o real, dirá ele.

${ }^{9}$ Expressão usada por Otte (1994, p. 81).

\section{REFERÊNCIAS}

BENJAMIN, W. Franz Kafka: a propósito do décimo aniversário de sua morte. In: _. Magia e técnica, arte e política. 6. ed. São Paulo: Brasiliense, 1985a. v. 1, p. 137-164. Coleção Obras Escolhidas.

BENJAMIN, W. O narrador: considerações sobre a obra de Nikolai Leskov. In:__ Magia e técnica, arte e política. 6. ed. São Paulo: Brasiliense, 1985b. v. 1, p.197-221.Coleção Obras Escolhidas.

BENJAMIN, W. A obra de arte na era da reprodutibilidade técnica. In: Magia e técnica, arte e política. 6 ed. São Paulo, Brasiliense, 1985c. v. 1, p. 165196. Coleção Obras Escolhidas. 
BLANCHOT, M. La voz narrativa (O "ele", o ele neutro). In: a Kafka. México: Fondo de Cultura Económica, 1991. p. 229-237. . De Kafka

CAMPOS, G. Kafka inteiro em fragmentos. In: . Parábolas e fragmentos. São Paulo: Ediouro, 1987. p. 17-21.

CARONE, M. Duas novelas de primeira (1988). In: KAFKA, F. O veredicto/Na colônia Penal. São Paulo: Companhia das Letras, 1998. p. 73-81.

CARONE, M. Catorze contos exemplares. In: São Paulo: Companhia das Letras, 1999. p. 75-81. . Um médico rural (1988).

CARONE, M. O Fausto do século 20. Folha de São Paulo. São Paulo, 22 out. 2000.Caderno Mais!. Disponível em: <http://www1.folha.uol.com.br/fsp/mais/ fs2210200003.htm>. Acesso em: 10 mar. 2010. Acesso restrito aos assinantes.

CLAUDEL, P. O pai humilhado (1915-1916). Petrópolis: Vozes, 1967.

GAGNEBIN, J. M. História e narração em Walter Benjamin. São Paulo: Perspectiva, 1994.

GOMES, R. M. de M. A escrita freudiana do pai-sintoma. Ágora, Rio de Janeiro, v. 6. n. 2. jul./dez. 2003. p. 271-288.

FREUD, S. O mal estar na civilização (1930). In: . Obras psicológicas completas de Sigmund Freud. Rio de Janeiro: Imago. v. XXI, p.75-174. Edição Standard Brasileira.

LACAN, J. O Mito Individual do Neurótico (1952). Rio de Janeiro: J. Zahar, 2008.

LACAN, J. O Seminário: a transferência (1961). Rio de Janeiro: J. Zahar, 1992. Livro 8.

LACAN, J. Subversão do sujeito e dialética do desejo no inconsciente freudiano (1960). In: . Escritos. Rio de Janeiro: J. Zahar, 1998. p. 807-842.

LACAN, J. O Seminário: a ética da psicanálise (1960). Rio de Janeiro: J. Zahar, 1988. Livro 7.

LACAN, J. Televisão (1974). In: . Outros Escritos. Rio de Janeiro: J. Zahar, 2003. p. 508-543.

LYOTARD, J. F. O pós-moderno. Rio de janeiro: José Olympio, 1993. 
MILLER, J. A. Clínica do supereu (1981). In: . Conferencias porteñas:. Buenos Aires: Paidós, 2009. Tomo I, p. 125-142.

OTTE, G. Linha, choque e mônada: tempo e espaço na obra tardia de Walter Benjamin. Tese (doutorado) Faculdade de Letras/PósLit, Universidade Federal de Minas Gerais, 1994.

KAFKA, F. A metamorfose (1915). Rio de Janeiro: BUP, 1965.

KAFKA, F. Parábolas e fragmentos. São Paulo: Ediouro, 1987.

KAFKA, F. Carta de 12.6.38 a Sholem. Novos Estudos CEBRAP, São Paulo, n. 35, p.100-106, mar. 1993. Tradução de Modesto Carone.

KAFKA, F. O Veredicto (1912)/Na Colônia Penal (1914). São Paulo: Companhia das Letras, 1998.

KAFKA, F. Um médico rural: pequenas narrativas. São Paulo: Companhia das Letras, 1999.

KAFKA, F. Carta a meu pai. São Paulo: Martin Claret, 2001a.

KAFKA, F. O Processo. São Paulo: Martin Claret, 2001 b.

ROSA, M. “A arte aplicada à psicanálise". In: Opção Lacaniana, Revista Brasileira Internacional de Psicanálise, São Paulo, n. 32, p. 48-51, dez. $2001 .$.

WEBER, M. A ética protestante e o espirito do capitalismo. São Paulo: Martin Claret, 2010.

ZIZEK, S. Le surmoi bureacrate. In: . L'Ane, Le Magazine Freudien, Paris. n. 8, p. 24-25, janv.-févr. 1983.

Recebido em: 13 de julho de 2010 Aceito em: 10 de maio de 2011 